\title{
POTENTIAL USE OF BUDDLEJA THYRSOIDES FOR THE CONTROL AND PREVENTION OF AMERICAN FOULBROOD DISEASE
} IN HONEY BEES

\author{
Aline A. Boligon ${ }^{1 *}$ \\ Mariana Piana ${ }^{1}$ \\ Thiele F. de Brum ${ }^{1}$ \\ Robson B. de Freitas ${ }^{2}$ \\ Leticia Nunes ${ }^{1}$ \\ Lauren Pappis ${ }^{1}$ \\ Camilla F. S. Alves ${ }^{3}$ \\ Rodrigo A. Vaucher ${ }^{3}$ \\ Roberto C. V. Santos ${ }^{3}$ \\ Margareth L. Athayde ${ }^{1}$ \\ 'Departamento de Farmácia Industrial, \\ Universidade Federal de Santa Maria, CEP 97105-900, Santa Maria, RS, Brazil \\ ¿University of León, León 24071, Spain \\ 3UNIFRA - Centro Universitário Franciscano \\ Rua dos Andradas, 1614 - Centro, Santa Maria, RS, 97010-032, Brazil \\ *corresponding author: alineboligon@yahoo.com.br \\ Received 29 July 2014; accepted 12 November 2014
}

Abstract

Paenibacillus larvae is the causative agent of American foulbrood (AFB), a severe disease that affects the larvae of the honeybees. The use of plant extracts are considered to be an alternative way of controlling the disease. In this study, the in vitro antimicrobial activity of Buddleja thyrsoides Lam. against the Paenibacillus species, including P. Iarvae, was evaluated. In Mueller-Hinton broth, the minimal inhibitory concentration (MIC) was assessed using the microdilution method. All Paenibacillus species were sensitive to the crude extract and the fractions of $B$. thyrsoides. The ethyl acetate (EA) fraction showed a better result with MIC values of $1.68-3.36 \mathrm{mg} / \mathrm{mL}$, followed by butanolic (BU) (MIC = $2.18-6.54 \mathrm{mg} / \mathrm{mL})$, dichloromethane (DCM) $(7.40-14.80 \mathrm{mg} / \mathrm{mL})$, and crude extract (CE) $(7.51-16.90 \mathrm{mg} / \mathrm{mL})$. The toxic effect of the CE and fractions of $B$. thyrsoides against bees were also evaluated using the spraying application method with the same concentrations of MICs. Bee mortality was evident in treatment with DCM fractions only, while $C E, E A$, and $B U$ extracts showed no toxic effects after 15 days of observation. Furthermore, phenolic acids, tannins, and flavonoids were identified and quantified by highperformance liquid chromatography (HPLC), and may be partially responsible for the antimicrobial properties observed. These results show, for the first time, that $B$. thyrsoides might be a natural alternative for the prevention/control of AFB.

Keywords: Antibacterial activity, bee survival, Buddleja thyrsoides, HPLC, Paenibacillus larvae.

\section{INTRODUCTION}

The medicinal properties of plants have been investigated in recent scientific developments throughout the world, due to their potent biological activities and economic viability (Dasari et al., 2012). Several studies describe such biological activities of plants as antibacterial, antifungal, and antiviral. These activities are related to the presence of a diverse group of chemical compounds including phenolics, flavonoids, glycosides, steroids, and alkaloids (Boligon et al., 2012a; 2012b; 2013b).
American foulbrood (AFB) is among the most severe bacterial diseases affecting honeybee larvae (Apis mellifera $L$.). This disease causes the decline of the population. American foulbrood can also lead to the death of the colony (Genersch et al., 2005; Santos et al., 2012). The causative agent is Paenibacillus larvae (White), a gram positive and sporeforming bacterium that is distributed worldwide (Spivak and Reuter, 2001; Genersch et al., 2006). American foulbrood is considered a global threat to apiculture because the etiologic agent produces environmentally stable spores which are very virulent, and resistant to 
heat, to desiccation, and to disinfectants (Genersch, 2010; Boligon et al., 2013a). Products derived from plants, such as propolis (Bastos et al., 2008; Mihai et al., 2012), essential oils (Albo et al., 2003; Santos et al., 2012); and extracts of Myrtus communis L., Eucalyptus dunnii (Maiden), Rosmarinus officinalis L., Zingiber officinale (Roscoe), Scutia buxifolia (Reissek), among other species (Flesar et al., 2010; Boligon et al., 2013a) were previously investigated and exhibited a growth-inhibitory effect against AFB.

Buddleja is a genus with pan tropical distribution that occurs in South Asia, Africa, and America (Mahlke et al., 2009). Species belonging to the Buddleja genus exhibit antibacterial, antihepatotoxic, pesticidal, anti-inflammatory, sedative, analgesic, and diuretic actions (Houghton et al., 2003; Mahlke et al., 2012). Buddleja thyrsoides Lam. (Scrophulariaceae) is commonly known as "Barbasco" or "Cambara-do-campo", in Brazilian folk medicine, its leaves and flowers are taken by drinking an infusion made with hot water for the treatment of bronchitis and a cough (Mahlke et al., 2013). Some previously published work by Mahlke et al. (2009; 2012; 2013) describes the essential oil composition, antimicrobial, and antioxidant activities, as well as the antiplatelet and acetylcholinesterase inhibition, of $B$. thyrsoides. Our work is the first time that antimicrobial activity of $B$. thyrsoides crude extract and fractions against the Paenibacillus species have been evaluated. Toxicity against the honey bee, Apis mellifera, was also investigated. Furthermore, phenols and flavonoids compounds were identified and quantified by high-performance liquid chromatography (HPLC/DAD).

\section{MATERIAL AND METHODS}

\section{Plant collection}

Leaves of Buddleja thyrsoides were collected in São Luiz Gonzaga, State of Rio Grande do Sul, Brazil, on July of 2006. For future reference, exsiccate was archived as voucher specimens in the herbarium of the Department of Biology at the Federal University of Santa Maria by the register number SMDB 10125.

\section{Extraction and partition of the leaves}

Air dried and powdered leaves of Buddleja thyrsoides (420 g) were extracted using ethanol $(70 \% \mathrm{v} / \mathrm{v})$ at room temperature, and daily agitation which was done for 7 days. After filtration, the extract was evaporated under reduced pressure to remove the ethanol in order to obtain a water suspension that was sequentially extracted at room temperature with dichloromethane, ethyl acetate, and $n$-butanol ( $3 \times 100 \mathrm{~mL}$ for each solvent). The yield of the dichloromethane fraction (DCM) was $13.06 \mathrm{~g}$ or 3.11\%; ethyl acetate fraction (EA) was $12.85 \mathrm{~g}$ our 3.06\%; and $n$-butanol fraction (BU) was $21.55 \mathrm{~g}$ our $5.13 \%$. A new amount of the same batch of plant material (100 g) was extracted with ethanol $(70 \%)$ at room temperature for seven days to afford the crude extract (CE) which was used in this study, with a yield of $11.7 \mathrm{~g}$ our $11.7 \%$.

\section{Microorganisms tested}

In this study, six isolates of the Paenibacillus species from the collection of The Ministry of Agriculture (LANAGRO/RS), Brazil, were used. The test organisms included isolates of $P$. alginolyticus, $P$. pabuli, $P$. azotofixans, $P$. borealis, $P$. validus, and $P$. larvae (ATCC 9545). The microorganisms were grown in MuellerHinton broth (Difco, Sparks, Maryland, USA) at $37^{\circ} \mathrm{C}$ for $24 \mathrm{~h}$, and maintained on slopes of nutrient agar (Difco).

\section{Determination of the minimum inhibitory concen- tration}

The minimum inhibitory concentrations (MIC) of crude extract, fractions, and compounds identified in $B$. thyrsoides, were determined by microdilution techniques in Mueller-Hinton broth (Difco) for the Paenibacillus species (CLSI, 2008). The assay was carried out in 96-well microtitre plates. Each sample was mixed with an inoculum prepared in the same medium, at a density adjusted per tube to 0.5 of the McFarland scale $\left(1.5 \times 10^{8} \mathrm{CFU} / \mathrm{mL}\right)$ and diluted 1:10 for the broth microdilution procedure. Microtitre trays were incubated at $37^{\circ} \mathrm{C}$. The MICs were recorded after $24 \mathrm{~h}$ of incubation. The minimum inhibitory concentration was defined as the lowest concentration of compounds that inhibits bacterial growth. This test was performed in triplicate on separate occasions. As an indicator of bacterial growth, 2,3,5-triphenyltetrazolium chloride was used. The solution of DMSO (5\%, v/v) was simultaneously assayed as the negative control. Analyses were carried out in duplicate and one blank for each concentration of samples was used.

\section{Toxicity assay}

The crude extract and fractions of $B$. thyrsoides were dissolved in DMSO to reach the final concentrations of $11.27,7.40,2.18$, and $1.68 \mathrm{mg} / \mathrm{mL}$ for $C E, D C M, B U$, and $E A$, respectively. The final concentration of DMSO was $5 \% \mathrm{v} / \mathrm{v}$; a value that did 
not cause interference in the antimicrobial activity. These concentrations used in the toxicity test were established from the determination of MIC values (Tab. 1). The spraying application method was performed according to Santos et al. (2012). Petri dishes $(150 \times 15 \mathrm{~mm})$ padded with absorbent filter paper on the inner bottom and with an extra lid of plastic mesh were used. Six adult worker bees were placed in every modified Petri dish. Then, one $\mathrm{mL}$ of each concentration (crude extract and fractions) was individually sprayed on the bees through the plastic lid using a hand sprayer. A device with a water solution of sugar (approximate concentration) was placed inside each unit as food for the bees. Six bees in a modified Petri dish sprayed with DMSO $(5 \%, v / v)$ were included as the negative control. Six bees in a modified Petri dish sprayed with $0.07 \%$ Deltamethrin (DTT) (Pirisa-Piretro Industrial Ltd, Brazil) were included as the positive death control. Four replicates for each experimental group were run. Bioassay dishes were placed in incubators at $28 \pm 1{ }^{\circ} \mathrm{C}$ and $60 \%$ relative humidity. Bee mortality was evaluated every day, for 15 days.

\section{HPLC analysis}

High-performance liquid chromatography (HPLC) was used to analyse CE and DCM, EA and BU fractions of $B$. thyrsoides leaves. Reverse-phase chromatographic analyses were carried out in isocratic conditions using C- 18 column $(4.6 \times 250 \mathrm{~mm})$ packed with $5-\mu \mathrm{m}$ in diameter particles; the mobile phase was methanolacetonitrile-water (40:15:45, v/v/v) containing 1.0\% acetic acid. The mobile phase was filtered through a $0.45-\mathrm{Im}$ membrane filter and then degassed by an ultrasonic bath, prior to use. Stock solution of gallic acid, caffeic acid, chlorogenic acid, ellagic acid, catechin, epicatechin, quercetin, isoquercitrin, rutin, and kaempferol standard reference were prepared in the HPLC mobile phase at a concentration range of $0.020-0.250 \mathrm{mg} / \mathrm{mL}$ (Boligon et al., 2013b). Quantification was carried out by the integration of the peak using the external standard method. The flow rate was $0.8 \mathrm{~mL} / \mathrm{min}$, injection volume was $40 \mu \mathrm{L}$, and detection was done at $257 \mathrm{~nm}$ for gallic acid, $280 \mathrm{~nm}$ for catechin and epicatechin, $325 \mathrm{~nm}$ for caffeic, ellagic, and chlorogenic acids, and $365 \mathrm{~nm}$ for quercetin, isoquercitrin, kaempferol, and rutin. The chromatographic peaks were confirmed by comparing their retention time and UV spectra with those of the reference standards and by spiking the isolated compounds in the plant sample. All chromatographic operations were performed at room temperature and in triplicate. The limit of detection
(LOD) and the limit of quantification (LOQ) were calculated based on the standard deviation of the responses and the slope using three independent analytical curves. The limit of detection and the limit of quantification were calculated as 3.3 and $10 \mathrm{r} / \mathrm{S}$, respectively, where $r$ is the standard deviation of the response and $S$ is the slope of the calibration curve (Boligon et al., 2012c).

\section{Statistical analysis}

Differences in survival after 15 days of observation were assessed by Kaplan-Meier analysis followed by the Logrank test. All statistical analyses were performed with the software package GraphPad Prism 4.00 for Windows (GraphPad Software, San Diego, CA, USA). Results of the HPLC-DAD quantification were considered statistically significant when $p<0.001$ by Tukey test.

\section{RESULTS}

\section{Antimicrobial susceptibility test and determina- tion of MIC}

All Paenibacillus species were susceptible to the assessed CE, DCM, EA, and BU of the $B$. thyrsoides. In addition, caffeic acid, ellagic acid, and quercetin also showed antimicrobial activity against the PaenibacilIus species. The MICs of these samples ranged from 1.68 to $16.90 \mathrm{mg} / \mathrm{mL}$ (Tab. 1).

\section{Lethal concentration on bees}

The bees treated with $C E, E A$, and $B U$ fractions of $B$. thyrsoides showed similar results to the results observed in the negative control group, throughout the whole observation time. No mortality of bees was observed for the 15 days of treatment (Fig. 1). Bee mortality was evident only in the treatment with the DCM fraction and DTT (the positive control group). Within 24 hrs after the treatment, all bees were dead in the positive control group. Bees treated with the DCM fraction showed a mortality index of about $10 \%$ per day until day 3 , with $70 \%$ survival at the end of the experiment (Fig. 1).

\section{Phytochemical analysis}

HPLC profile of CE, DCM, EA, and BU fractions of the $B$. thyrsoides were obtained (Fig. 2). These regions showed typical patterns of UV absorption, supporting the presence of gallic acid, catechin, chlorogenic acid, caffeic acid, ellagic acid, epicatechin, rutin, isoquercitrin, quercetin, and kaempferol. Retention time and quantifications of these compounds is showed in Table 2. The EA, BU, and DCM fractions 
Minimum inhibitory concentration of Buddleja thyrsoides crude extract

Table 1. and fractions on the Paenibacillus species

\begin{tabular}{lccccccc}
\hline \multirow{2}{*}{ Microorganisms } & \multicolumn{3}{c}{$\begin{array}{c}\text { Buddleja thyrsoides } \\
\text { (mg/mL) }\end{array}$} & \multicolumn{3}{c}{$\begin{array}{c}\text { Compounds } \\
\text { (mg/mL) }\end{array}$} \\
\cline { 2 - 8 } & CE & DCM & EA & BU & CA & EL & QU \\
\hline P. larvae (ATCC 9545) & 11.27 & 7.40 & 1.68 & 2.18 & 6.54 & 2.18 & 3.36 \\
\hline P. borealis & 16.90 & 14.80 & 3.36 & 6.54 & 9.93 & 2.18 & 6.54 \\
\hline P. validus & 11.27 & 7.40 & 1.68 & 2.18 & 16.90 & 11.27 & 14.80 \\
\hline P. pabuli & 7.51 & 7.40 & 1.68 & 2.18 & 16.90 & 6.54 & 11.27 \\
\hline P. alginolyticus & 11.27 & 7.40 & 3.36 & 2.18 & 7.51 & 16.90 & 16.90 \\
\hline P. azotofixans & 11.27 & 7.40 & 1.68 & 2.18 & 11.27 & 16.90 & 9.93 \\
\hline
\end{tabular}

Crude extract (CE), dichloromethane fraction (DCM), ethyl acetate fraction (EA),

butanolic fraction (BU), caffeic acid (CA), ellagic acid (EL), and quercetin (QU).

Table 2.

Compounds determined by HPLC in Buddleja thyrsoides (\%).

Retention time-Rt (minutes)

\begin{tabular}{cccccc}
\hline \multirow{2}{*}{ B. thyrsoides } & \multirow{2}{*}{ Rt } & CE & DCM & EA & BU \\
\cline { 3 - 6 } & & \multicolumn{4}{c}{ Stem bark } \\
\hline Gallic acid & 11.45 & $0.70 \pm 0.02^{\mathrm{a}}$ & $2.18 \pm 0.04^{\mathrm{a}}$ & $1.42 \pm 0.01^{\mathrm{a}}$ & $1.57 \pm 0.01^{\mathrm{a}}$ \\
\hline Catechin & 16.03 & $1.23 \pm 0.03^{\mathrm{b}}$ & $2.87 \pm 0.01^{\mathrm{b}}$ & $2.05 \pm 0.04^{\mathrm{b}}$ & $2.13 \pm 0.04^{\mathrm{b}}$ \\
\hline Chlorogenic acid & 22.17 & $4.81 \pm 0.01^{\mathrm{c}}$ & $2.30 \pm 0.01^{\mathrm{c}}$ & $5.03 \pm 0.01^{\mathrm{c}}$ & $1.61 \pm 0.05^{\mathrm{a}}$ \\
\hline Caffeic acid & 25.01 & $5.17 \pm 0.01^{\mathrm{d}}$ & $4.91 \pm 0.02^{\mathrm{d}}$ & $4.65 \pm 0.01^{\mathrm{d}}$ & $4.58 \pm 0.09^{\mathrm{c}}$ \\
\hline Ellagic acid & 30.11 & $2.92 \pm 0.03^{\mathrm{e}}$ & $4.25 \pm 0.03^{\mathrm{e}}$ & $7.54 \pm 0.02^{\mathrm{e}}$ & $3.11 \pm 0.04^{\mathrm{d}}$ \\
\hline Epicatechin & 34.68 & $2.75 \pm 0.03^{\mathrm{e}}$ & $2.09 \pm 0.01^{\mathrm{c}}$ & $4.89 \pm 0.03^{\mathrm{d}}$ & $1.54 \pm 0.01^{\mathrm{a}}$ \\
\hline Rutin & 40.93 & $2.74 \pm 0.02^{\mathrm{e}}$ & - & $2.11 \pm 0.03^{\mathrm{b}}$ & $4.86 \pm 0.03^{\mathrm{e}}$ \\
\hline Quercetin & 44.85 & $4.69 \pm 0.01^{\mathrm{c}}$ & - & $5.49 \pm 0.01^{\mathrm{e}}$ & $6.95 \pm 0.01^{\mathrm{f}}$ \\
\hline Isoquercitrin & 51.34 & $0.76 \pm 0.03^{\mathrm{a}}$ & - & $2.91 \pm 0.04^{\mathrm{f}}$ & $4.93 \pm 0.02^{\mathrm{e}}$ \\
\hline Kaempferol & 60.13 & $2.35 \pm 0.08^{\mathrm{f}}$ & - & $1.32 \pm 0.02^{\mathrm{a}}$ & $2.01 \pm 0.01^{\mathrm{b}}$ \\
\hline
\end{tabular}

Results are expressed as mean \pm standard deviation (SD) of three determinations. Different letters in each column represent significant differences using analysis of variance followed by

Tukey test ( $p$ values $<0.001$ were considered as significant).

Crude extract (CE), dichloromethane fraction (DCM), ethyl acetate fraction (EA), butanolic fraction (BU).

presented a higher quantity of phenolics compounds (37.87\%, 33.29\%, and $28.12 \%$, respectively) when compared with CE (18.60\%). The calibration curve, limit of detection, and limit of quantification of the standards used in HPLC are shown in Table 3.

\section{DISCUSSION}

The present work reports the first study on antimicrobial activity of Buddleja thyrsoides crude extract and fractions against various Paenibacillus species, showing an important antimicrobial effect in all strains tested. Better results were shown by EA and $\mathrm{BU}$ fractions for $P$. larvae with MIC of 1.68 and $2.18 \mathrm{mg} / \mathrm{mL}$, respectively (Tab. 1). These results are in agreement with Boligon et al. (2013a), that also describes the best result for the EA fraction of S. buxifolia against the Paenibacillus species, using the same methodology. Flesar et al. (2010) described 13 natural compounds and 16 crude extracts that exhibited an antimicrobial effect against $P$. larvae with MICs values ranging from 2 to $256 \mu \mathrm{g} / \mathrm{mL}$, using the broth microdilution method. In the case of the extracts, Humulus lupulus L. and Myrtus communis $L$. exhibited the highest growth-inhibitory effect. Propolis extract was also described as 
Calibration curves of the standards used in HPLC.

LOD and LOQ variations for compounds $(\mu \mathrm{g} / \mathrm{mL})$

\begin{tabular}{cccc}
\hline Standards used & calibration curve & LOD & LOQ \\
\hline Gallic acid & $Y=12673 x+1125.6(r=0.9999)$ & 0.022 & 0.067 \\
\hline Catechin & $Y=14037 x+1281.5(r=0.9985)$ & 0.008 & 0.026 \\
\hline Chlorogenic acid & $Y=13582 x+1175.2(r=0.9997)$ & 0.019 & 0.057 \\
\hline Caffeic acid & $Y=13841 x+1197.4(r=0.9999)$ & 0.035 & 0.014 \\
\hline Ellagic acid & $Y=13841 x+1197.4(r=0.9999)$ & 0.027 & 0.082 \\
\hline Epicatechin & $Y=11876 x+1183.7(r=0.9991)$ & 0.041 & 0.135 \\
\hline Rutin & $Y=14739 x+1356.5(r=0.9994)$ & 0.034 & 0.103 \\
\hline Quercetin & $Y=12685 x+1327.1(r=0.9998)$ & 0.030 & 0.091 \\
\hline Isoquercitrin & $Y=14052 x+1285.5(r=0.9992)$ & 0.007 & 0.023 \\
\hline Kaempferol & $Y=13674 x+1189.3(r=0.9999)$ & 0.024 & 0.072 \\
\hline
\end{tabular}

LOD: limit of detection; LOQ: limit of quantification.

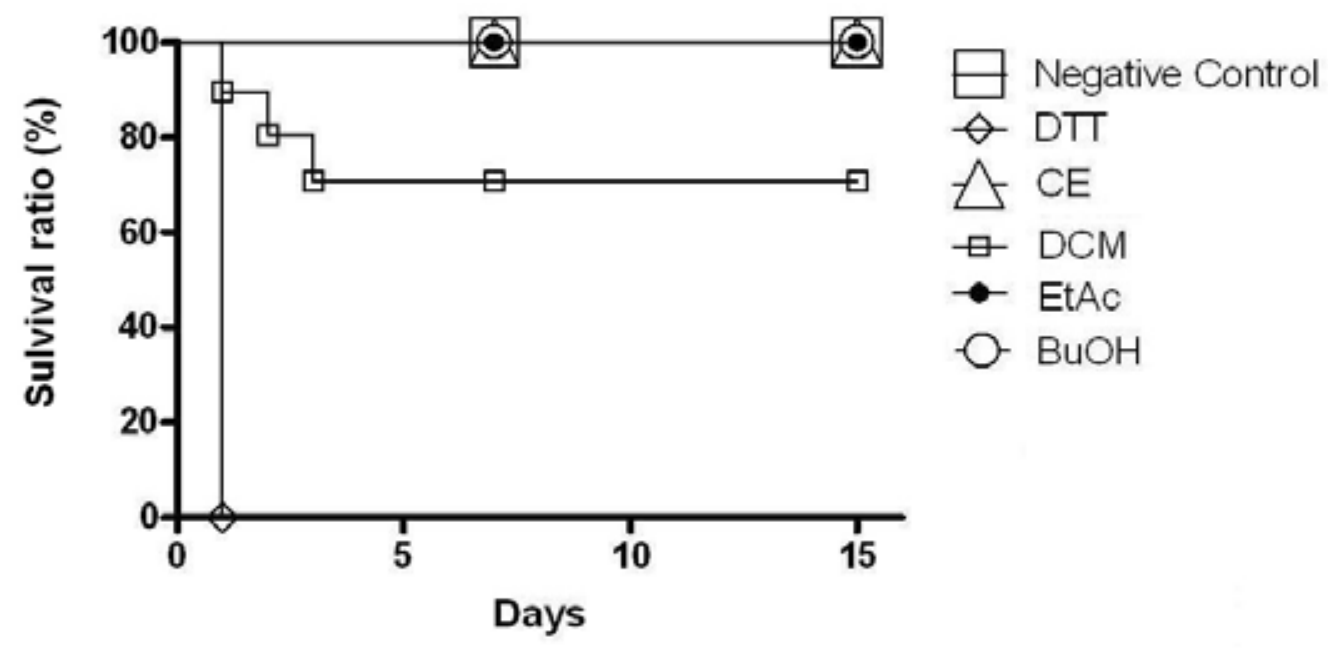

Fig. 1. Effects of Buddleja thyrsoides Lam. spraying applications on Apis mellifera L.

a natural alternative for the control of AFB (Bastos et al., 2008; Finstrom and Spivak, 2010).

In addition, previous works reported the antibacterial properties of $B$. thyrsoides against such diverse pathogens as Staphylococcus aureus, Saccharomyces cerevisiae, Pseudomonas aeruginosa, Candida glabrata, and Prototheca zopfii (Mahlke et al., 2009). Based on earlier works and the present experiments with different fractions, an obvious antibacterial activity could be related to the chemical composition of the plant species. It is known that EA and $\mathrm{BU}$ fractions are rich in phenolic acids, tannins and flavonoid compounds, such as, gallic acid, chlorogenic acid, caffeic acid, ellagic acid, catechin, epicatechin, rutin, quercetin, isoquercitrin, and kaempferol (Fig. 2; Tab. 2). Therefore, flavonoids and phenolic compounds identified in $B$ thyrsoides were also tested against the Paenibacillus species. However only, caffeic acid, ellagic acid, and quercetin inhibited the growth of the Paenibacillus species, with MICs values ranging from 2.18 to $16.90 \mathrm{mg} / \mathrm{mL}$ (Tab. 1). These compounds may contribute in part to the good antimicrobial activity found in this study, since they are present in large quantities in the most effective fractions of $B$. thyrsoides. It has been suggested that the antimicrobial activity could be due to the additional effect or may be synergism of several chemical compounds, since various plant extracts and fractions show higher antimicrobial activity than any of the single compounds separately tested (Flesar et al., 2010; Boligon et al., 2013a). The inhibitory effect of a propolis extract and S. buxifolia fractions against $P$. larvae was attributed to a possible synergism of flavonoids and phenols (Mihai et al., 2012; Boligon et al., 2013a). 

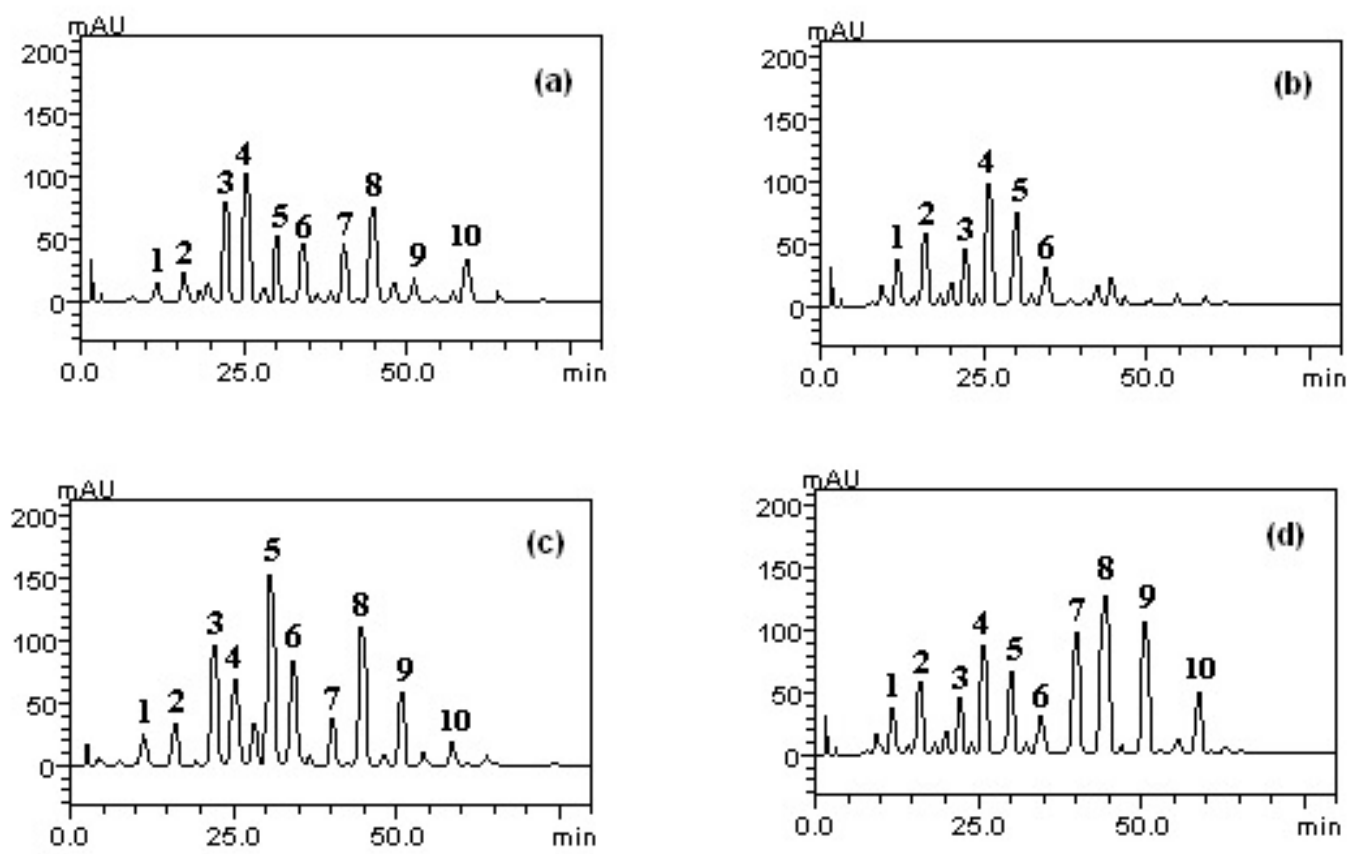

Fig. 2. Representative high performance liquid chromatography profile of Buddleja thyrsoides.

Crude extract (a), dichloromethane fraction (b), ethyl acetate fraction (c), and butanolic fraction (d).

Gallic acid (1), catechin (2), chlorogenic acid (3), caffeic acid (4), ellagic acid (5), epicatechin (6), rutin

(7), isoquercitrin (8), quercetin (9), and kaempferol (10).

In order to verify the possible toxic effects, the $C E$, $\mathrm{DCM}, \mathrm{EA}$, and $\mathrm{BU}$ fractions of $B$. thyrsoides were sprayed on $A$. mellifera. The results when using $C E, E A$, and $B U$ fractions were similar to the control group. No toxic effects or animal deaths were caused. However, DCM fraction caused the death of bees in the concentration of $7.4 \mathrm{mg} / \mathrm{mL}$, resulting in a survival rate of approximately $70 \%$ after 15 days of observation. The extracts of S. buxifolia and copaiba oil showed no toxic effects after 15 and 10 days following the treatment, respectively, using the same method described in the present article (Santos et al., 2012; Boligon et al., 2013a). Brazil has a very rich biological diversity. There are numerous medicinal and pharmacological properties in this vast diversity that should be explored. In the area of honeybee health, the application of alternative natural substances might be a novel method to control AFB. An optimal elimination of $P$. larvae in $A$. mellifera colonies would involve treatments with acceptable antimicrobial activity with no side effects on $A$. mellifera. This treatment would mean a further minimising of residues in honey and could act as a viable alternative to reduce antimicrobial resistance.

\section{CONCLUSION}

Brazil has a very rich biological diversity. The numerous medicinal and pharmacological properties should be explored. In the area of honeybee health, Buddleja extracts might be an unexplored way for future research involving alternative natural substances used to control the AFB. Elimination of $P$. larvae in $A$. mellifera colonies involves treatments with acceptable antimicrobial activity with no side effects on $A$. mellifera. Residues in honey and wax would be minimised. These treatments offer a viable alternative to reduce antimicrobial resistance. In this context, $B$. thyrsoides is a potentially useful alternative for suppressing bacterial diseases that affect the honeybee.

\section{ACKNOWLEDGEMENTS}

The authors thank the financial support of CNPq/ CAPES/FAPERGS (Conselho Nacional de Desenvolvimento Científico e Tecnológico/Fundação de Amparo a Pesquisa do Rio Grande do Sul/Coordenação de Aperfeiçoamento de Pessoal de Nível Superior)/ Brazil. 


\section{J. APRC. SCLI. VOL. 58 NO. 2 2014}

\section{REFERENCES}

Albo G. N., Henning C., Ringuelet J., Reynaldi F. J., Giusti M. R., Alippi A. M. (2003) Evaluation of some essential oils for the control and prevention of American Foulbrood disease in honey bees. Apidologie 34: 417-427.

Bastos E. M. A. F., Simone M., Jorge D. M., Soares A. E. E., Spivak M. (2008) In vitro study of the antimicrobial activity of Brazilian propolis against Paenibacillus larvae. Journal of Invertebrate Pathology 97: 273-281.

Boligon A. A., Brum T. F." Frilhich J. K. Froeder A. L. F." Athayde M. L. (2012a) HPLC/DAD profile and determination of total phenolics, flavonoids, tannins and alkaloids contents of Scutia buxifolia Reissek stem bark. Research Journal of Phytochemistry 6: 84-91.

Boligon A. A., Janovik V., Boligon A. A., Pivetta C. R., Pereira R. P., Rocha J. B. T., Athayde M. L. (2012b) HPLC analysis of polyphenolic compounds and antioxidant activity in Nasturtium officinale. International Journal of Food Properties 16: 61-69.

Boligon A. A., Sagrillo M. R., Machado L. F., Filho O. S., Machado M. M., Cruz I. B. M., Athayde M. L. (2012c) Protective effects of extracts and flavonoids isolated from Scutia buxifolia Reissek against chromosome damage in human Iymphocytes exposed to hydrogen peroxide. Molecules 17:5757-5769

Boligon A. A., Brum T. F., Zadra M., Piana M., Alves C. F. S., Fausto V. P., Júnior V. S. B., Vaucher R. A., Santos R. C. V., Athayde M. L. (2013a) Antimicrobial activity of Scutia buxifolia against the honeybee pathogen Paenibacillus larvae. Journal of Invertebrate Pathology 112: 105-107.

Boligon A. A., Kubiça T. F., Mario D. N., Brum T. F., Piana M., Weiblen R., Lovato L., Alves S. H., Santos R. C. V., Alves C. F. S., Athayde M. L. (2013b) Antimicrobial and antiviral activity-guided fractionation from Scutia buxifolia Reissek extracts. Acta Physiologiae Plantarum 35: 2229-2239.

CLSI (2008) Methods for dilution antimicrobial susceptibility tests for bacteria that grow aerobically, ninth ed. Approved standard M7-A6 37(2). Clinical and Laboratory Standards Institute. Wayne (PA), USA. 88 pp.

Dasari N. P., Rao B. G., Rao E. S., Rao T. M., Praneeth D. V. S. (2012) Quantification of phytochemical constituents and in vitro antioxidant activity of Synadium grantii. Free Radicals and Antioxidants 2: 68-72.
Finstrom M. S., Spivak M. (2010) Propolis and bee health: the natural history and significance of resin use by honey bees. Apidologie 41: 295-311.

Flesar J., Havlik J., Kloucek P., Rada V., Titera D., Bednar M., Stropnicky M., Kokoska L. (2010) In vitro growth-inhibitory effect of plant-derived extracts and compounds against Paenibacillus larvae and their acute oral toxicity to adult honey bees. Veterinary Microbiology 145: 129-133.

Genersch E. (2010) Honey bee pathology: current threats to honey bees and beekeeping. Applied Microbiology and Biotechnology 87 (1): 87-97.

Genersch E., Ashiralieva A., Fries I. (2005) Strain- and genotype-specific differences in virulence of Paenibacillus larvae subsp. larvae, a bacterial pathogen causing American Foulbrood Disease in honeybees. Applied and Environmental Microbiology 71 (1 1): 7551-7555.

Genersch E., Forsgren E., Pentikainen J., Ashiralieva A., Rauch S., Kilwinski J., Fries I. (2006) Reclassification of Paenibacillus larvae subsp. pulvifaciens and Paenibacillus larvae subsp. larvae as Paenibacillus larvae without subspecies differentiation. International Journal of Systematic and Evolutionary Microbiology 56: 501-51 1.

\section{GraphPad Software. San Diego, CA, USA.}

Houghton P. J., Abraham Y., Mensah A. Y., Yong-Hong L. (2003) Terpenoids in Buddleja: relevance to chemosystematics, chemical ecology and biological activity. Phytochemistry 64: 385-393.

Mahlke J. D., Boligon A. A., Machado M. M., Athayde M. L. (2012) In vitro toxicity, antiplatelet and acetylcholinesterase inhibition of Buddleja thyrsoides Lam. leaves. Natural Product Research 26(23): 2223-2226.

Mahlke J. D., Boligon A. A., Machado M. M., Athayde M. L. (2013) Composition of the essential oil of Buddleja thyrsoides Lam. leaves from Brazil. Natural Product Research 27 (14): 1319-1322.

Mahlke J. D., Boligon A. A., Machado M. M., Spader T. B., Alves S. H., Canto-Dorow T., Athayde M. L. (2009) In vitro antimicrobial and antioxidant activities of a crude extract and fractions from Buddleja thyrsoides Lam. leaves. Quimica Nova 32: 277-281.

Mihai C. M., Marghitas L. A., Dezmirean D. S., Chirila F., Moritz R. F. A., Schluns H. (2012) Interactions among flavonoids of propolis affect antibacterial activity against the honeybee pathogen Paenibacillus larvae. Journal of Invertebrate Pathology 1 10: 68-72. 
Santos R. C. V., Alves C. F. S., Schneider T., Lopes L. Q. S., Spivak M., Reuter G. S. (2001). Resistance to American Aurich C., Giongo J. L., Brandelli A., Vaucher R. A. (2012) foulbrood disease by honey bee colonies Apis mellifera Antimicrobial activity of Amazonian oils against Paeni- bred for hygienic behavior. Apidologie 32: 555-565. bacillus species. Journal of Invertebrate Pathology 109: 265-268. 